\title{
The problems of determining the canon in the plastic folklore of the Sakha (Yakuts)
}

\author{
Sargylana Nikiforova ${ }^{1, *}$, Galina Popova $^{1}$, and Ekaterina Dyachkovskaya $^{1}$ \\ ${ }^{1}$ North-Eastern Federal University, 677027, 58 Belinsky str., Yakutsk, Russia
}

\begin{abstract}
In the conditions of erosion of specificity and weakening of ethnic cultures identity, massive imitation of authenticity undertaken by the cultural bearers themselves with the aim of commercializing becomes an additional threat to its preservation. The authors believe that these threats can be minimized if "structuring elements" of this culture are determined. In particular, the popularization of canonical national forms of culture can contribute to this. The undividedness of oral folk art and decorative applied art is the basic characteristics of folklore. In addition to it, the structural and content components of the artistic canon in the folk art of Sakha (Yakuts) are named in the paper. In traditional culture, the thing made according to the canon, determines the behavior of its owner and makes him correspond to the expected visions of the ethnic community; moreover, it models the scenario of his fate. The problems of interaction between the evolution of style and the author's deviations from the canon are partially touched upon in the article. With regard to the plastic folklore, these are the best, typical, and familiar features that are not presented as a sum of skills and techniques of craft, but as a creative interpretation of the national master. In the outstanding works of folk art, these ornamental forms are deliberately chosen, taking into account the chromatic code of culture, the composition of which refers to the national picture of the world. The pictorial canon in the plastic folklore captures and transmits the rules for visualizing the spiritual experience of the people from generation to generation. In fact, it forms the framework of culture, and it is the canon that provides for "not a common expression of faces" of each culture.
\end{abstract}

\section{Introduction}

Against the backdrop of the mass commercialization of ethnic cultures in the format of creative industries, which, as a rule, takes exotic, catchy, and deliberately primitive images, the issues associated with the increasing cases of simulation of traditional culture, called "staged" (imitated) authenticity become specifically acute. The latter is fraught with irreversible consequences for the culture also because it is initiated directly by the representatives of ethnoses with the best intentions: "to attract investments", "to save and preserve", etc. In this situation, the definition of the canon of folk artistic culture is seen by the author as the opportunity to contribute to the preservation of those cultural features that

\footnotetext{
* Corresponding author: nsv2107@ mail.ru
} 
determine the specificity of culture of this people and bring it closer to the preservation of authentic forms.

\section{Literature Review}

In modern science, inseparability, collectivity, stereotyping, variability and canonicity are typically mentioned among the basic characteristics of folk culture (please, refer to P.G. Bogatyrev, M.S. Kagan, E.M. Meletinsky, S.Yu. Neklyudov, M.A. Nekrasov, B.N. Putilov, I.E. Fadeeva, N.A. Khrenov, and others). These features also characterize folk art, which is considered here as a complex artistic system with specific laws of structure and development. The term "plastic folklore", proposed by M.S. Kagan is used in this paper, because, in our opinion, it points out precisely the syncretic nature of folk art (Kagan, 1972, p. 199). Such an understanding of the undivided nature of oral folk art and decorative and applied art is typical for Yakut researchers, who, on the basis of works of folk art, came, at the same time, to the conclusion that "the circle of decorative motifs and images typical for wooden products is characteristic of Yakut household art as a whole" (Potapov, 1972, pp. 123). It is hardly possible to exhaustively define the system of material and technical, and figurative and expressive means that has developed in the work of masters, but we will try to identify the basic structural and content components of the artistic canon in the plastic folklore of Sakha (Yakuts).

The heyday of the Yakut folk art culture falls on the period from the end of the $19^{\text {th }}$ century to the first quarter of the $20^{\text {th }}$ century. This is the time of the formation of the artistic canon in all forms of Yakut folk art, and that is why most researchers defined it as the period of classics (I.A. Potapov, V.Kh. Ivanov, R.S. Gavrilieva, Z.N. Unarova, I.V. Pokatilova, etc.). For example, R.S. Gavrilieva, who was one of the first to study the national costume of the Yakuts, notes: "The folk art traditions of the Yakuts flourished in the $19^{\text {th }}$ and early $20^{\text {th }}$ centuries" (Gavrilieva, 1998, p. 85). Since "the tasks of both artistic embodiment and content, directly dependent on many components of culture that created this canon are closely intertwined with the concept of "canon"' (Zinchenko, 2010), we consider it necessary to clarify the implications of this multi-faceted term. Understood as a "system of ... rules and norms immanent in the art of any cultural and historical period or artistic direction that determines the main principles of artistic thinking that fixes the basic structural and constructive patterns of specific art forms setting the matrix to the creative process" (Bychkov, 2011, p. 284), the canon is represented both as a "path of creativity", "having form-creating meaning" (Nekrasov, 1971, p. 30), and as a subject seen as a normative pattern. A.F. Losev proposed the definition of the canon, which we use in this paper as a basic one: “... the canon is a quantitative and structural model of a work of art of this style, which, being a certain socio-historical indicator, is interpreted as the principle of constructing a known set of works. Such a model turns out to be a pattern and criterion for positive evaluation of the works of art that embody the artistic canon" (Losev, 1973, p. 15).

\section{Results}

The works of folk art, whether they are represented in ceramics, sewing or jewelry, despite all their stereotyping, are not "the mechanical reproduction of certain standard scenes using the same proportions with the help of auxiliary meshes" (Rauschenbach, 2002, p. 211). In everyday life and in the ritual, the properties of the objective world manifest themselves in different ways. In the ritual, the utilitarian function of the object recedes, and its plastic image becomes "equal in rights with the person acting" (Fadeeva, 1978, p. 289). As A.K. Baiburin notes, in the ritual "any thing became a model of the Universe, ... of a microcosm" 
(Baiburin, 1991, pp. 36-37). In the situation of the rite, when the "transcoding of reality" takes place (Putilov, 2003, p. 100), all culture codes are included and act in one direction: visual, verbal, chromatic, culinary, and other; they do not repeat, but complement each other, expand and strengthen each other's functions that I.E. Fadeeva called "mutual interpretation" (Fadeeva, 1978, p. 289).

\section{Methods}

Interaction of traditions of various cultures of the Northeast Asia enriched the Yakut folk art. Over the centuries the artistic traditions of the Turkic tribes have borrowed elements of the autochthonous Paleo-Asiatic cultures - Even, Evenk, Yukaghir, Chukchi and Dolgan, later (with the development of Siberia), Russian culture was included in this synthesis. By the end of the $18^{\text {th }}$ - beginning of the $19^{\text {th }}$ century they, "as a result of centuries-old contacts" (Ivanov, 2001, p. 127), finally formed into an organic and distinctive cultural system of the Sakha (Yakuts). It was in the $19^{\text {th }}$ century, when archaic traditions were artistically rethought by the masters that was accompanied by a loss of the sacral meanings of the craft, replaced in the course of time by a simplified poetization of ancient subjects, signs, and symbols. Meanwhile, "a master, once a sacred person, tried to go beyond the closed world, splashing out inner energy into traditional forms of folk art" (Pokatilova, 2013 , p. 84). The outgoing generation of the bearers of authentic folklore more and more allowed demonstrating the secret, for centuries, verbally transmitted knowledge of the masters, in order, as they thought, to avoid its ultimate loss. In fact, there was a profanation of traditional forms. By traditionalism, we mean not the mechanical imitation of the images, forms and methods of antiquity, but the stability of preserving the national specifics in the "visual design of worldview ideas" (Zinchenko, 2010) that does not exclude continuity in the development of new trends in the life of the ethnos. The works of plastic folklore are characterized by the constructive clarity of form, generality, and expressive conventionality of images and ornamentality. In the best examples, the folk master intuitively and unerringly comprehends the connection between the constructive and decorative aspects of the subject.

The classical canon in the plastic folklore, a set of unwritten rules of folk art, as it was formed by the $19^{\text {th }}$ century in the culture of the Sakha (Yakuts), suggests, first, the use of natural local material (bone, birch bark, wood, metal, fur and leather). Secondly, the chromatic code of culture determines the choice of a soft, warm color scale (not acidic aggressive scenic coloring), and all shades of processed skin: from light ocher to orange and black, with delicate inclusions of bright color. Thirdly, for centuries a polished set of preferred technologies has been developed for the processing of leather and fur, bone and metal. Fourthly, ornamentality is a key characteristic of the plastic folklore of the Sakha (Yakuts). Almost complete ornamentation with precise knowledge of the symbolism and location of the pattern, when the image is the "semantic center of the thing", and also the "principle of its organization" (Fadeeva, 1978, p. 297). Fifthly, this is the underlined designation of the boundaries of the place, determined by the landscape and climate. In the vast expanses the Yakuts would not have survived, if each time did not rigidly denote the boundaries of their location. It is interesting to mention the note of one of the folk masters: "In the Middle World all living things have their own developmental limits, ... therefore everything must be enclosed, fenced off" (Nikiforova, 2010, p. 57), and the evidence of this is the abundance of hedges in the space inhabited by the Yakuts. Sixthly, as a consequence, it is a rigid composition structure.

These rules developed historically, in the course of mastering of all the best, created by the work of many generations of masters, by the collective experience. The work of folk art is perceived as already familiar and therefore does not carry information, but acts as a 
"trigger" that provokes its "self-growth, ... structurally organizes the consciousness of the addressee" (Lotman, 1973, p. 18). Especially if we take into account that in the traditional culture the relations "Man - Subject" were based on a fundamentally different basis than today, at that time each subject was individual, qualitatively defined, and received an independent being already in production. Let us consider this situation using the example of the craft practices of the Sakha (Yakuts). The potter, after the birth of a child, was ordered a new pot, which predicted the future not only of the child, but of the whole family. If the vessel cracked during firing, it served as a foretaste of disease and unhappiness. Before placing in the furnace, it was filled with a liquid mixture of milk and manure, and by the nature of the drawing from the boiling jets judged the fate of the child. And lastly, if after drying, instead of a clean ringing from a blow to the pot, a deaf sound was heard - this, too, was interpreted as a bad omen. "Living" things, endowed with their own will and character ... acting as a partner of their owner in everyday life and ritual ... repeated his life path" (Toporov, 1994, p. 62). A thing in traditional culture, made according to the canon is the key condition, since it determines the behavior of its owner, makes it correspond to the expectations of the ethnic community; moreover, it models the scenario of his fate.

It can be argued that the canon is not so much "repeating" but directing, acting as an "l'avant-texte", the components of which represent "the mentalities of the tradition that make up its cognitive space" (Neklyudov, 2001). It is also possible to present it as a "superstructure for the rules of its construction" in the terminology of S.Yu. Neklyudov.

\section{Discussions}

The natural-geographical factor and local cultural traditions are the basis of folk art. To them, in addition to the mentioned above, we refer epic stories, ornamental motifs, artistic techniques, and well-established forms. They are important, but they lose all meaning beyond that organic whole, into which the particulars merge in a certain time and in each of the crafts, creating original features of folk art, that G.K. Wagner defined as "the whole" (Wagner, 1982, p. 50), and V.B. Rauschenbach - as a "the highest sense", which "must be seen directly", as in the icon (Rauschenbach, 2002, p. 272). The meanings indicated above and forming the specificity of culture constitute its symbolic capital, which determines the habitus of each particular culture. The use of the concept of "habitus" proposed by P. Bourdieu, which he treats as "the systems of stable and transferable dispositions, the structured structures predisposed to function as structuring structures, that is, the principles that generate and organize practices and representations", can be productive in the context of the definition of an artistic canon (Bourdieu, 2001, p.102). And one more issue, the problem of the relation between the canon and the freedom of the master's work, not touched here, does not lose its sharpness.

The development of traditions does not consist in the formal signs of art or in their mechanical sum, but it is, first of all, in accordance with the spirit of the times and the people, in the synthesis of the traditional and the new, the preservation of the national proper. "Every style is an expression of the spiritual state of the people of their time ... people do not stop in their development ... they are constantly changing ... and changes in the artistic style are inevitably associated with these changes" (Saltykov, 1969). The problem of the interaction of the evolution of style and authorial deviations from the canon with reference to ancient Russian art was considered by G.K. Wagner, who noted that "the character of the author's deviations from the canon is the evolution of the style" (Wagner, 1987, p. 158). In our understanding, these are the best, typical, habitual traits that are not presented as a sum of skills and techniques of craft, but as a creative interpretation of a folk master. 


\section{Conclusions}

In the outstanding works of folk art, these ornamental forms are deliberately chosen, with the observance of the chromatic code of culture, the composition of which refers to the national picture of the world, to the inner spiritual essence, when the artistic image does not lose "moral, natural, cosmic, religious content" (Nekrasov, 2009). Yu.M. Lotman points to another function of the canon: "The texts of canonical art ... are powerful regulators and builders of the human personality and culture" (Lotman, 1973, p. 22). The pictorial canon in the plastic folklore captures and transmits from generation to generation the rules for visualizing the spiritual experience of the people, and in fact, it forms the framework of culture. It is the canon that provides for "not a common expression of faces" of each culture.

\section{References}

1. A. K. Bayburin, Ethno-cultural functions of culture (Moscow, 1991)

2. P. Bourdieu, Practical meaning (Aletheia, St. Petersburg; Institute of Experimental Sociology, Moscow, 2001)

3. V. Bychkov, Aesthetics (Academic Project, Mir Foundation, Moscow, 2011)

4. G. K. Wagner, Problems of folk art (Moscow, 1982)

5. G. K. Wagner, Canon and style in old Russian art (Art, Moscow, 1987)

6. R. S. Gavrilieva, Clothing of the Sakha people at the end of the XVIIth - the middle of the XVIII century (Nauka, Novosibirsk, 1998)

7. S. A. Zinchenko, Specificity of the artistic image and idea of the canon in the art of early Scythian time (http://old.portal-slovo.ru/rus/art).

8. V. Kh. Ivanov, Ethno-cultural interrelations and mutual influences among the peoples of the North-East of Siberia (on the basis of traditional decorative and applied art) (Nauka, Novosibirsk, 2001)

9. M.S. Kagan, Art morphology: Historical and theoretical study of the internal structure of the art world (Art, Leningrad, 1972)

10. AF Losev, The Canon problem in the ancient and medieval art of Asia and Africa: collection of articles (Moscow, 1973)

11. S. Yu. Neklyudov, Living Antiquity, 4 (2001)

12. M. A. Nekrasova, Decorative Art of the USSR, 5 (1971)

13. M. A. Nekrasova, The place of folk art as a spiritual phenomenon in the modern culture of Russia (http://rusk.ru).

14. S. V. Nikiforova, Symbolism of female jewelry: cultural codes of the traditional daily life of Sakha (Yakuts) (Asterion, St. Petersburg, 2010)

15. I. V. Pokatilova, Plastic folklore in the artistic culture of Yakutia (Nauka, Novosibirsk, 2013)

16. I. A. Potapov, Yakut folk carving on wood (Knizhnoye Izdatelstvo, Yakutsk, 1972)

17. B. N. Putilov, Folklore and Folk Culture (Petersburg Oriental Studies, St. Petersburg, 2003)

18. B. V. Raushenbach, Geometry of the picture and visual perception (ABC-Classics, St. Petersburg, 2002)

19. A. B. Saltykov, The nearest art (Enlightenment, Moscow, 1969) 
20. V. N. Toporov, The concept of fate in the context of different cultures (Moscow, 1994)

21. I. E. Fadeeva, Questions of Art Studies, 1 (1978) 